\title{
Preoperative Embolization Reduces the Risk of Cathecolamines Release at the Time of Surgical Excision of Large Pelvic Extra-Adrenal Sympathetic Paraganglioma
}

\author{
Nicola Di Daniele, ${ }^{1}$ Maria Paola Canale, ${ }^{1}$ Manfredi Tesauro, ${ }^{1}$ Valentina Rovella, \\ Roberto Gandini, ${ }^{2}$ Orazio Schillaci, ${ }^{3}$ Federica Cadeddu, ${ }^{4}$ and Giovanni Milito ${ }^{4}$ \\ ${ }^{1}$ Department of Internal Medicine, Rome Tor Vergata University, Viale Oxford 81, 00133 Rome, Italy \\ ${ }^{2}$ Department of Radiology, Rome Tor Vergata University, Viale Oxford 81, 00133 Rome, Italy \\ ${ }^{3}$ Department of Nuclear Medicine, Rome Tor Vergata University, Viale Oxford 81, 00133 Rome, Italy \\ ${ }^{4}$ Department of Surgery, Rome Tor Vergata University, Viale Oxford 81, 00133 Rome, Italy
}

Correspondence should be addressed to Nicola Di Daniele, didaniele@med.uniroma2.it

Received 14 May 2012; Accepted 1 August 2012

Academic Editors: C. Capella and A. Sahdev

Copyright (C) 2012 Nicola Di Daniele et al. This is an open access article distributed under the Creative Commons Attribution License, which permits unrestricted use, distribution, and reproduction in any medium, provided the original work is properly cited.

\begin{abstract}
A 30-year-old woman with severe hypertension was admitted to the hospital with a history of headache, palpitations, and diaphoresis following sexual intercourse. Twenty-four hour urinary excretion of free catecholamines and metabolites was markedly increased as was serum chromogranin A. Computed tomography scan revealed a large mass in the left adnex site and magnetic resonance imaging confirmed the computer tomography finding, suggesting the presence of extra-adrenal sympathetic paraganglioma. I-metaiodobenzyl guanidine scintigram revealed an increased uptake in the same area. Transcatheter arterial embolization of the mass resulted in marked decreases in blood pressure and urinary excretion of free catecholamines and metabolites. Surgical excision of the mass was then accomplished without complication. Preoperative embolization is a useful and safe procedure which may reduce the risk of catecholamines release at the time of surgical excision in large pelvic extra-adrenal sympathetic paraganglioma.
\end{abstract}

\section{Introduction}

Previous reports have described the use of trancatheter arterial embolisation (TAE) in patients with pheochromocytoma. Preoperative embolization in both adrenal and extraadrenal locations (including thoracic, intrapericardial, and left atrium [1-3]) has been shown to reduce the risk of catecholamines release during manipulation of the tumor at the time of surgery. Management of massive retroperitoneal haemorrhage has also been successfully performed with this procedure $[4,5]$. Treatment of malignant pheochromocytoma [6] or its metastatic lesions [7-12], particularly liver metastasis $[13,14]$, has been performed too. Percutaneous transcatheter interventional procedures are also increasingly being employed in the management of gynaecological and obstetric disorders [15-17], including fibroids and postpartum haemorrhage $[18,19]$, and the management of tumor-related bleeding caused by both gynaecological malignancies and tumor metastatic to the vulvovaginal area $[20,21]$.

No previous reports have described of the use of TAE in the management of pelvic extra-adrenal sympathetic paraganglioma. The aim of the present study is to describe the usefulness of TAE in the preoperative management of pelvic extra-adrenal sympathetic paraganglioma in a young female patient.

\section{Case Report}

A 30-year-old caucasian woman was admitted to the hospital following syncope associated with a pounding headache, epistaxis, and blurred vision.

Her past medical history included uncomplicated removal of an ovarian cyst and cholecystectomy at age 16 and 22 
years, respectively. She delivered vaginally two children at age 23 and 25 years. She was in good health until a year prior to this presentation when she developed frequent postprandial vomiting and weight loss. Type 2 diabetes mellitus was diagnosed by oral glucose tolerance test and she was treated with metformin ( $1500 \mathrm{mg}$ od). The patient also reported frequent attacks of severe headache, particularly during and following sexual intercourse. More recently, she had developed nocturia.

Physical examination revealed severe hypertension $(240 / 150 \mathrm{mmHg})$, tachycardia $(150 \mathrm{bpm})$, and diaphoresis. Physical examination was otherwise unremarkable. Blood chemistry demonstrated hyperglicemia $(16.22 \mathrm{mmol} / \mathrm{L})$, elevated glycosylated haemoglobin $(57 \mathrm{mmol} / \mathrm{mol}$, normal range: $20-40 \mathrm{mmol} / \mathrm{mol}$ ), normal serum electrolytes, and liver and renal function. The EKG only showed sinus tachycardia (150 beats per minute).

The patient underwent biochemical screening for cause of secondary hypertension. Due to the severity of hypertension, a washout period from antihypertensive medications was not obtained. Serum chromogranin A ( $\mathrm{CgA})$ was elevated at $3819 \mu \mathrm{g} / \mathrm{L}$ (normal range: 19-98), and 24 hour urinary excretion of both free catecholamines (CATH) and metabolites was markedly increased. Urinary epinephrine (E) was $1876 \mathrm{nmol} / \mathrm{d}$ (normal limit 3$109 \mathrm{nmol} / \mathrm{d}$ ); norepinephrine (NE) was $130883 \mathrm{nmol} / \mathrm{d}$ (normal range $136-621 \mathrm{nmol} / \mathrm{d})$; normetanephrine (NMETH) was $196560 \mathrm{nmol} / \mathrm{d}$ (upper normal limit $2129.4 \mathrm{nmol} / \mathrm{d}$ ); metanephrine (METH) was $2621 \mathrm{nmol} / \mathrm{d}$ (normal range 0 $1622 \mathrm{nmol} / \mathrm{d}$ ); vanilmandelic acid (VMA) was $716 \mu \mathrm{mol} / \mathrm{d}$ (normal range 9.09-33.9 $\mu \mathrm{mol} / \mathrm{d}$ ). Twenty-four hour urinary cortisol was slightly elevated: $712 \mathrm{nmol} / \mathrm{d}$ (normal range: $77.2-590.7 \mathrm{nmol} / \mathrm{d})$. Plasma renin activity $(1.19 \mu \mathrm{g} / \mathrm{L} / \mathrm{h})$, plasma aldosterone $(6.81 \mathrm{nmol} / \mathrm{L})$, and plasma cortisol $(527.5 \mathrm{nmol} / \mathrm{L})$ were within normal limits. There was no left ventricular hypertrophy on transthoracic echocardiography.

A computed tomography (CT) scan revealed no adrenal abnormalities, but a large mass in the left adnex site $(7 \mathrm{~cm}$ of diameter) (Figure 1) was detected. Magnetic resonance imaging (MRI) was suggestive of an extraadrenal sympathetic paraganglioma (Figure 2). Whole-body I-metaiodobenzyl guanidine (MIBG) scintigraphy detected increased uptake in the same area (Figure 3 ) without any other pathological activity elsewhere. Biochemical screening for multiple endocrine neoplasia was negative. Antihypertensive drugs were used to manage hypertension, to control associated cardiovascular symptoms, and to prepare the patient for surgery. The patient was initially started on labetalol i.v. ( $100 \mathrm{mg}$ in $250 \mathrm{~mL}$ saline at $30 \mathrm{~mL} / \mathrm{h}$ ), increasing doses of oral doxazosin were then added (up to $8 \mathrm{mg} /$ day) while labetalol was tapered. Subsequently, oral atenolol (100 mg/day) was added to the therapy.

Percutaneous transarterial embolization (TAE) of the mass was successfully performed via the inferior mesenteric artery (Figure 4). This resulted in a marked decrease in plasma CgA $(1531 \mu \mathrm{g} / \mathrm{L})$ (Figure 5) and 24-hour urine excretion of VMA $(202 \mu \mathrm{mol} / \mathrm{d})$ and total free CATH and Metanephrines (102074 nmol/d) (Figure 6). Laparotomic excision

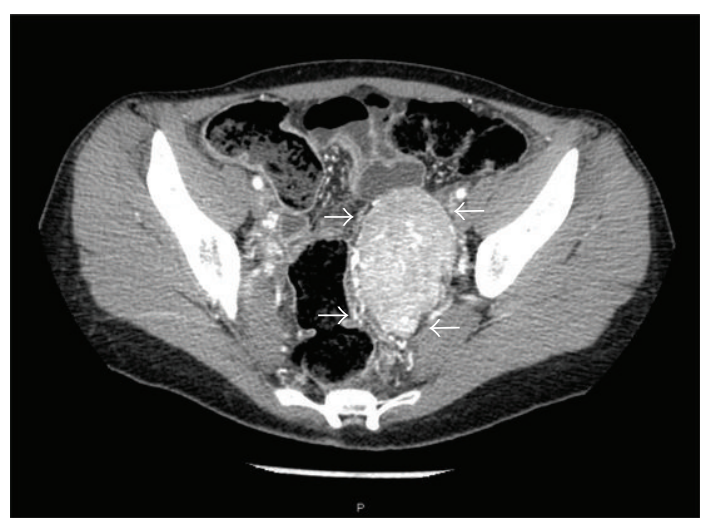

Figure 1: Enhanced pelvic CT scan showing a large mass in the left adnex site.

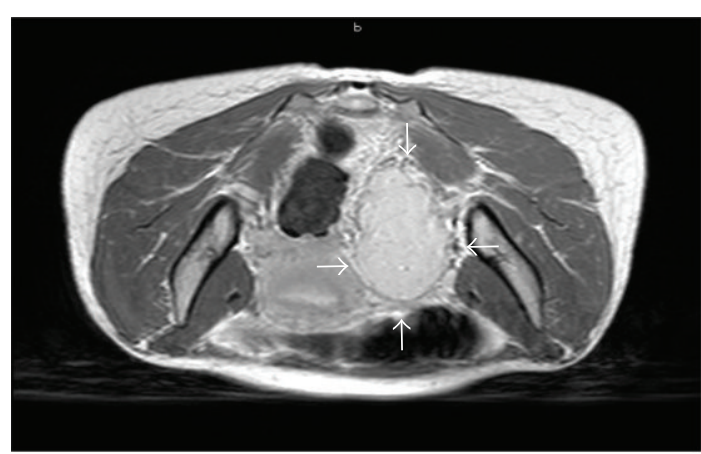

FIgure 2: Pelvic MRI suggestive of a parauterine left site extraadrenal sympathetic paraganglioma in the images obtained after i.v. injection of gadolinium: axial view.

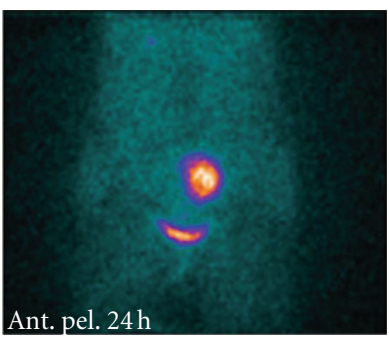

(a)

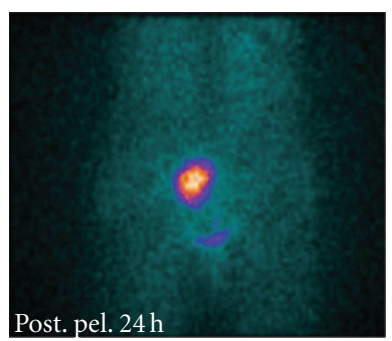

(b)
FIGURE 3: I-MIBG scintigraphy showing accumulation of radiopharmaceutical in the left paramedian site of the pelvis.

of a para-adnexal mass was performed after dissection of the tumour from the left iliac vessels (Figure 7).

Plasma CgA and 24-hour urine excretion of VMA and total free CATH and Metanephrines values following surgery are also shown in Figures 5 and 6, respectively. Histological findings were consistent with pheochromocytoma (paragangliomas synaptophysin, positive; CroA, positive; S-100, very few positive cells; Ki67, approximately $3 \%$ of positive cells). In the postoperative period, the patient did not require 


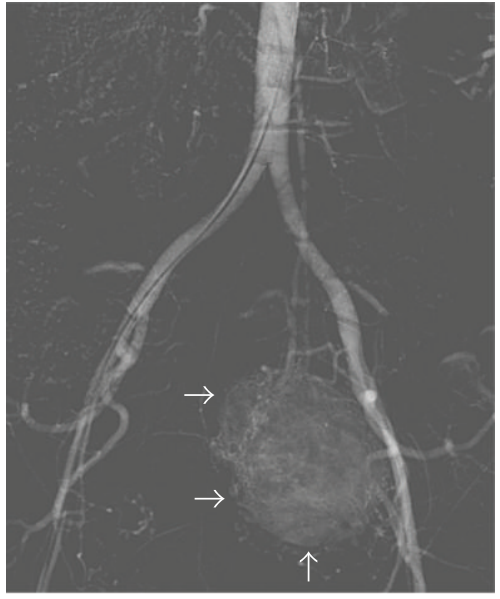

(a)

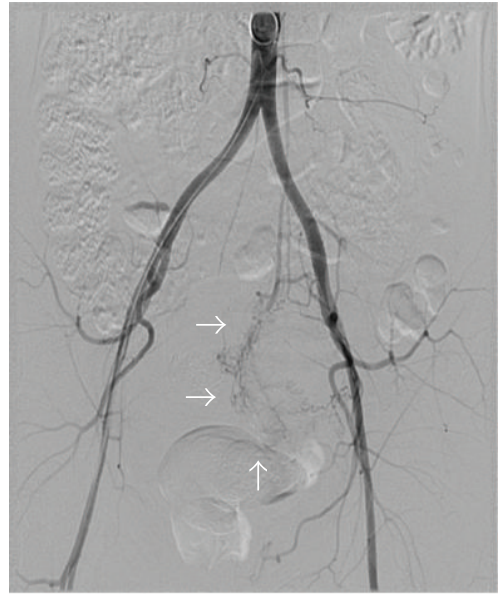

(b)

FIGURE 4: Angiography before and after TAE: tumour traces decreased in the target lesion after TAE.

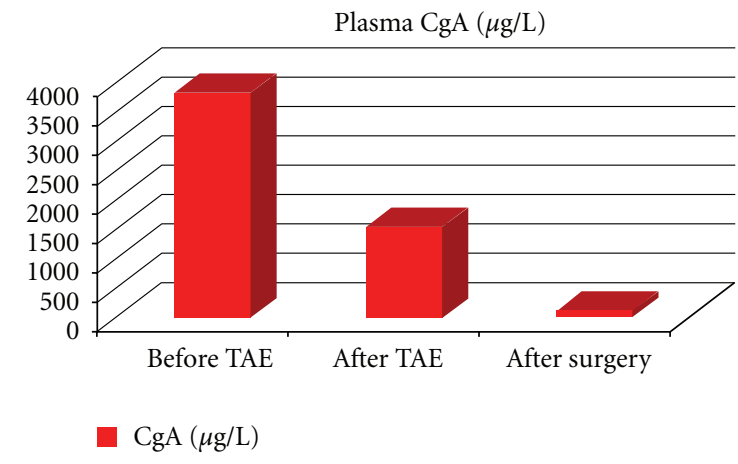

Figure 5: Changes in plasma CgA following TAE and surgery.

treatment for hypotension or hypoglycaemia. At followup, she is normotensive and has normal glucose tolerance on no antihypertensive or hypoglycaemic medications.

\section{Discussion}

In this case, despite the presence of the triad of headache, tachycardia and diaphoresis, which has been shown to have very high sensitivity for the diagnosis of pheochromocytoma [22], the temporal association of these features with sexual intercourse probably caused the delay of the diagnosis. This manifestation reflected its extra-adrenal location. Besides, this large extra-adrenal phaeochromocytoma was not associated with familial syndromes and was not metastatic. This variety of clinical features can explain why the differential diagnosis is often demanding [22]. In this patient, the diabetes initially predominated the clinical picture and disappeared after the removal of the tumour.

Although the onset of the tumor was unknown, its large size is consistent with its presence for at least few years. Interestingly, in this patient neither prior surgery, nor at the induction of anaesthesia nor during vaginal deliveries, hypertensive crises happened.

Hypertension was initially controlled with labetalol iv, an alpha-beta blocker agent, and then oral doxazosin, a selective alpha-receptor antagonis, added for few days prior to surgery. Many studies suggest that a long-lasting alphablockade is no longer necessary to prepare patients for surgery. Newell et al. reported that preoperative adrenergic blockade did not prevent severe intraoperative hypertension and that prolonged periods of preparations were not more effective in preventing intraoperative tachycardia and ventricular arrhythmias [23]. Boutros et al. reported similar perioperative results whether or not patients received preoperative alpha blockade [24]. Moreover, in a study of 114 patients who underwent removal of pheochromocytoma, fewer perioperative complications were observed in those not given alpha-blockers [25]. These results reflect the advances in anaesthetic and monitoring techniques and the availability of fast-acting drugs capable of correcting sudden changes in cardiovascular hemodynamics [22].

\section{Conclusion}

To our knowledge, this is the first report of the use of TAE in the management of pelvic extra-adrenal sympathetic paraganglioma. Marked decrease in circulating levels of catecholamines following TAE may be associated with lower risks of haemodynamic fluctuations during surgical manipulation of the tumour and in the postoperative period.

This paper demonstrates that TAE may have an important role in the preoperative management of large pelvic extra-adrenal sympathetic paragangliomas.

\section{Disclosure}

This study did not receive any specific grant from any funding agency in the public, commercial, or profit sector. 

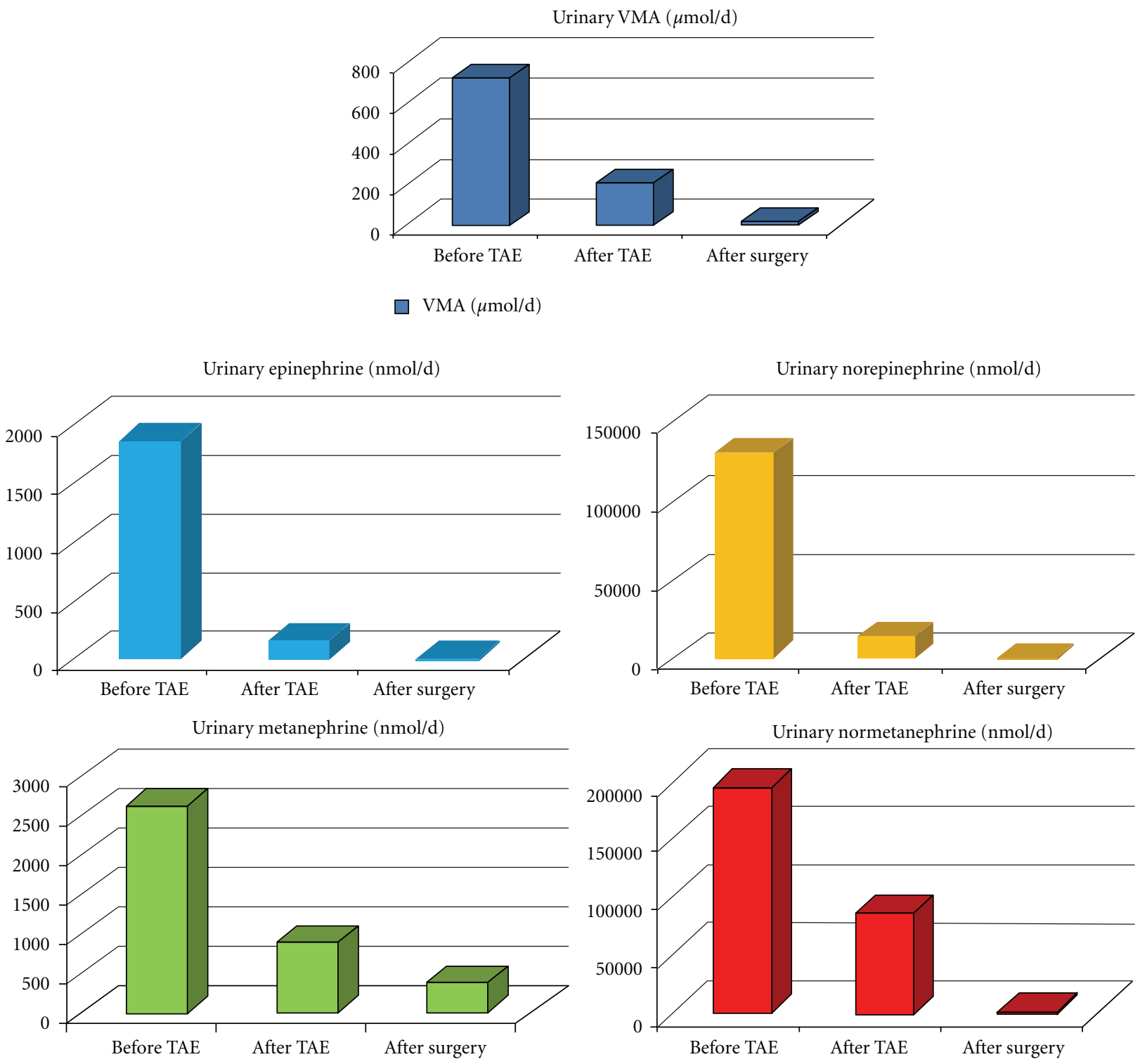

FIgure 6: Changes in $24 \mathrm{~h}$ urinary VMA, free CATH (E+NE), and Metanephrines (METH+NMETH) following TAE and surgery.

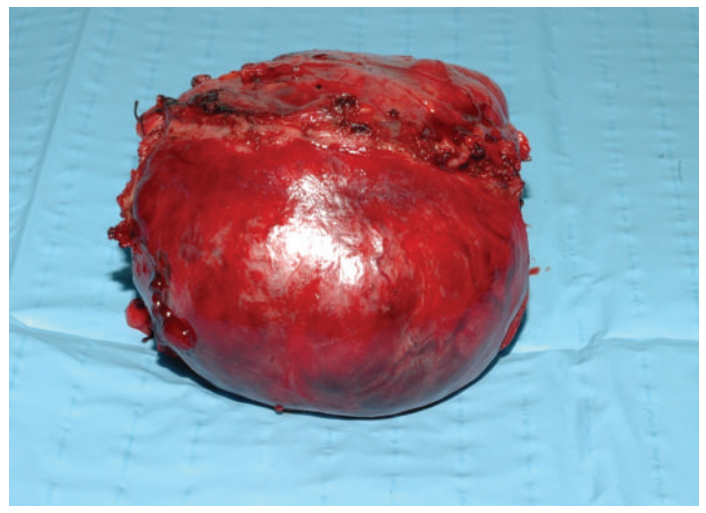

FIGURE 7: Resected paraadnexal extra-adrenal sympathetic paraganglioma.

\section{Conflict of Interests}

The authors declare that there is no conflict of interests that could be perceived as prejudicing the impartiality of the research reported.

\section{References}

[1] A. M. Ali, M. Devbhandari, A. Sastry, R. J. Ashleigh, and M. T. Jones, "Preoperative embolization followed by surgical excision of an intrapericardial pheochromocytoma," Annals of Thoracic Surgery, vol. 83, no. 1, pp. 302-304, 2007.

[2] E. Montana, X. Montana, R. Morera et al., "Functioning paraganglioma (pheochromocytoma) of the thorax: preoperative embolization," Journal of Thoracic and Cardiovascular Surgery, vol. 100, no. 4, pp. 626-628, 1990. 
[3] J. A. Horton, E. Hrabovsky, W. G. Klingberg, J. A. Hostler, and J. J. Jenkins, "Therapeutic embolization of a hyperfunctioning pheochromocytoma," American Journal of Roentgenology, vol. 140, no. 5, pp. 987-988, 1983.

[4] J. H. Park, K. P. Kang, S. J. Lee, C. H. Kim, T. S. Park, and H. S. Baek, "A case of a ruptured pheochromocytoma with an intratumoral aneurysm managed by coil embolization," Endocrine Journal, vol. 50, no. 6, pp. 653-656, 2003.

[5] R. J. Hendrickson, P. J. Katzman, R. Queiroz, J. V. Sitzmann, and L. G. Koniaris, "Management of massive retroperitoneal hemorrhage from an adrenal tumor," Endocrine Journal, vol. 48, no. 6, pp. 691-696, 2001.

[6] K. Homma, K. Hayashi, S. Wakino et al., "Primary malignant hepatic pheochromocytoma with negative adrenal scintigraphy," Hypertension Research, vol. 29, no. 7, pp. 551-554, 2006.

[7] S. Yamaguchi, K. Hida, N. Nakamura, T. Seki, and Y. Iwasaki, "Multiple vertebral metastases from malignant cardiac pheochromocytoma: case report," Neurologia MedicoChirurgica, vol. 43, no. 7, pp. 352-355, 2003.

[8] K. Nonaka, H. Makuuchi, Y. Naruse, T. Kobayashi, and M. Goto, "Surgical excision of malignant pheochromocytoma in the left atrium," The Japanese Journal of Thoracic and Cardiovascular Surgery, vol. 48, no. 2, pp. 126-128, 2000.

[9] S. Tanaka, T. Ito, J. Tomoda, T. Higashi, G. Yamada, and T. Tsuji, "Malignant pheochromocytoma with hepatic metastasis diagnosed 20 years after resection of the primary adrenal lesion," Internal Medicine, vol. 32, no. 10, pp. 789-794, 1993.

[10] S. Onohara, H. Kobayashi, N. Uchiyama, T. Sonoda, T. Oyama, and S. Shinohara, "A successfully treated case of malignant pheochromocytoma by arterial embolization using absolute ethanol," Nippon Igaku Hoshasen Gakkai zasshi, vol. 43, no. 1, pp. 1-8, 1983.

[11] J. B. Timmis, M. J. Brown, and D. J. Allison, “Therapeutic embolization of phaeochromocytoma," British Journal of Radiology, vol. 54, no. 641, pp. 420-422, 1981.

[12] H. D. Bunuan, M. Alltree, and K. A. Merendino, "Gel foam embolization of a functioning pheochromocytoma," American Journal of Surgery, vol. 136, no. 3, pp. 395-398, 1978.

[13] S. Hidaka, A. Hiraoka, H. Ochi et al., "Malignant pheochromocytoma with liver metastasis treated by transcatheter arterial chemo-embolization (TACE)," Internal Medicine, vol. 49, no. 7, pp. 645-651, 2010.

[14] D. Watanabe, A. Tanabe, M. Naruse et al., "Transcatheter arterial embolization for the treatment of liver metastases in a patient with malignant pheochromocytoma," Endocrine Journal, vol. 53, no. 1, pp. 59-66, 2006.

[15] D. M. Hovsepian, J. Bonn, D. J. Eschelman, M. J. Shapiro, K. L. Sullivan, and G. A. Gardiner Jr., "Fallopian tube recanalization in an unrestricted patient population," Radiology, vol. 190, no. 1, pp. 137-140, 1994.

[16] G. Casola, E. VanSonnenberg, H. B. D’Agostino, C. P. Harker, R. R. Varney, and D. Smith, "Percutaneous drainage of tuboovarian abscesses," Radiology, vol. 182, no. 2, pp. 399-402, 1992.

[17] J. M. Gooding, H. B. D’Agostino, and S. C. Plaxe, "Transcervical metallic stents for drainage of uterine collections," Journal of Vascular and Interventional Radiology, vol. 10, no. 5, pp. 629-633, 1999.

[18] M. Gonsalves and A. Belli, "The role of interventional radiology in obstetric hemorrhage," CardioVascular and Interventional Radiology, vol. 33, no. 5, pp. 887-895, 2010.

[19] H. K. Sidhu, G. Prasad, V. Jain, J. Kalra, V. Gupta, and N. Khandelwal, "Pelvic artery embolization in the management of obstetric hemorrhage," Acta Obstetricia et Gynecologica Scandinavica, vol. 89, no. 8, pp. 1096-1099, 2010.

[20] A. K. P. Lim, R. Agarwal, M. J. Seckl, E. S. Newlands, N. K. Barrett, and A. W. M. Mitchell, "Embolization of bleeding residual uterine vascular malformations in patients with treated gestational trophoblastic tumors," Radiology, vol. 222, no. 3, pp. 640-644, 2002.

[21] Y. Yamashita, M. Harada, H. Yamamoto et al., "Transcatheter arterial embolization of obstetric and gynaecological bleeding: efficacy and clinical outcome," British Journal of Radiology, vol. 67, no. 798, pp. 530-534, 1994.

[22] E. L. Bravo and R. Tagle, "Pheochromocytoma: state-of-theart and future prospects," Endocrine Reviews, vol. 24, no. 4, pp. 539-553, 2003.

[23] K. A. Newell, R. A. Prinz, M. H. Brooks et al., "Plasma catecholamine changes during excision of pheochromocytoma," Surgery, vol. 104, no. 6, pp. 1064-1073, 1988.

[24] A. R. Boutros, E. L. Bravo, G. Zanettin, and R. A. Straffon, "Perioperative management of 63 patients with pheochromocytoma," Cleveland Clinic Journal of Medicine, vol. 57, no. 7, pp. 613-617, 1990.

[25] J. C. Ulchaker, D. A. Goldfarb, E. L. Bravo, and A. C. Novick, "Successful outcomes in pheochromocytoma surgery in the modern era," Journal of Urology, vol. 161, no. 3, pp. 764-767, 1999. 


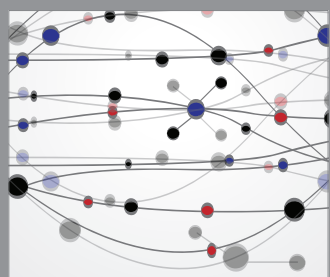

The Scientific World Journal
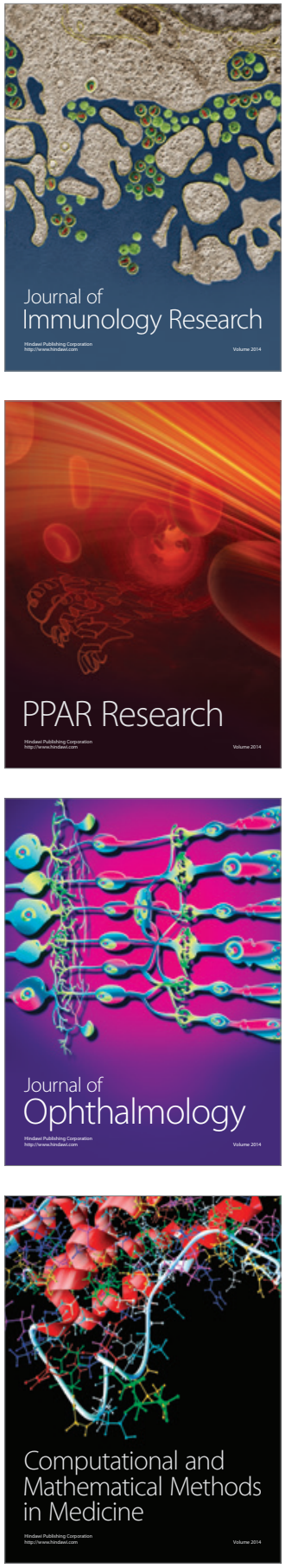

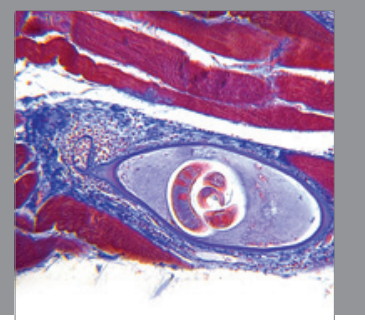

Gastroenterology

Research and Practice
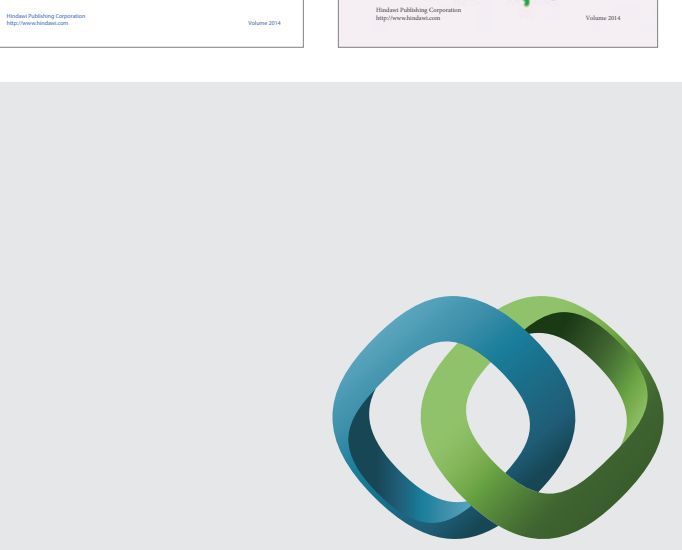

\section{Hindawi}

Submit your manuscripts at

http://www.hindawi.com
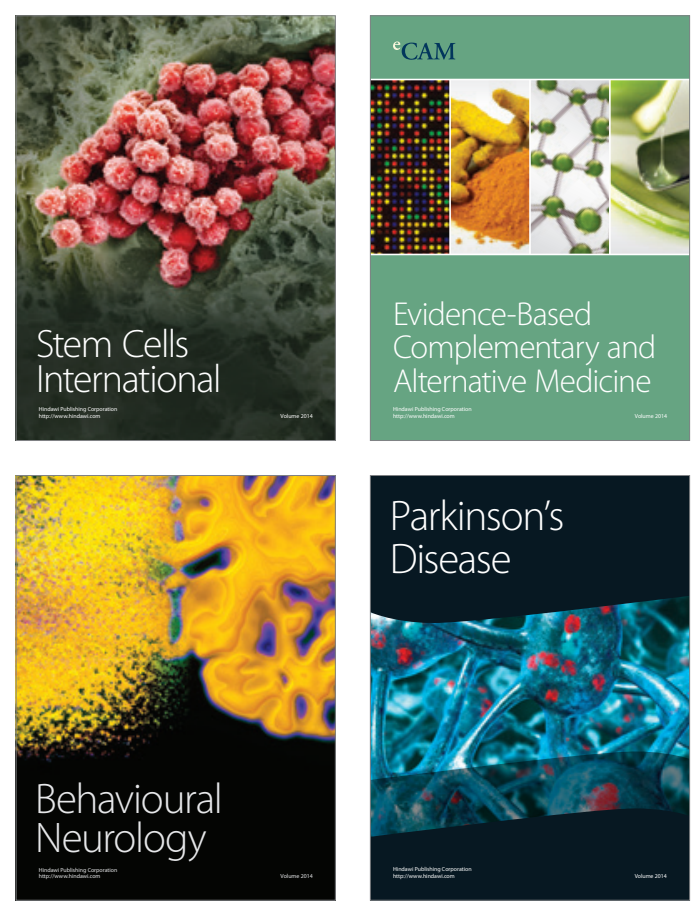

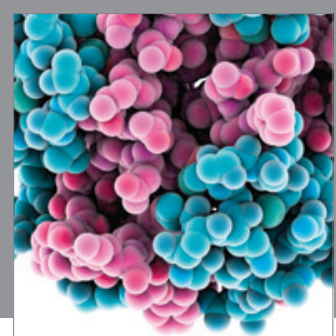

Journal of
Diabetes Research

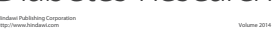

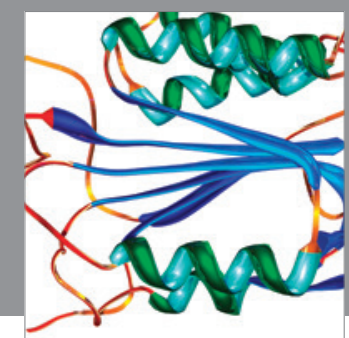

Disease Markers
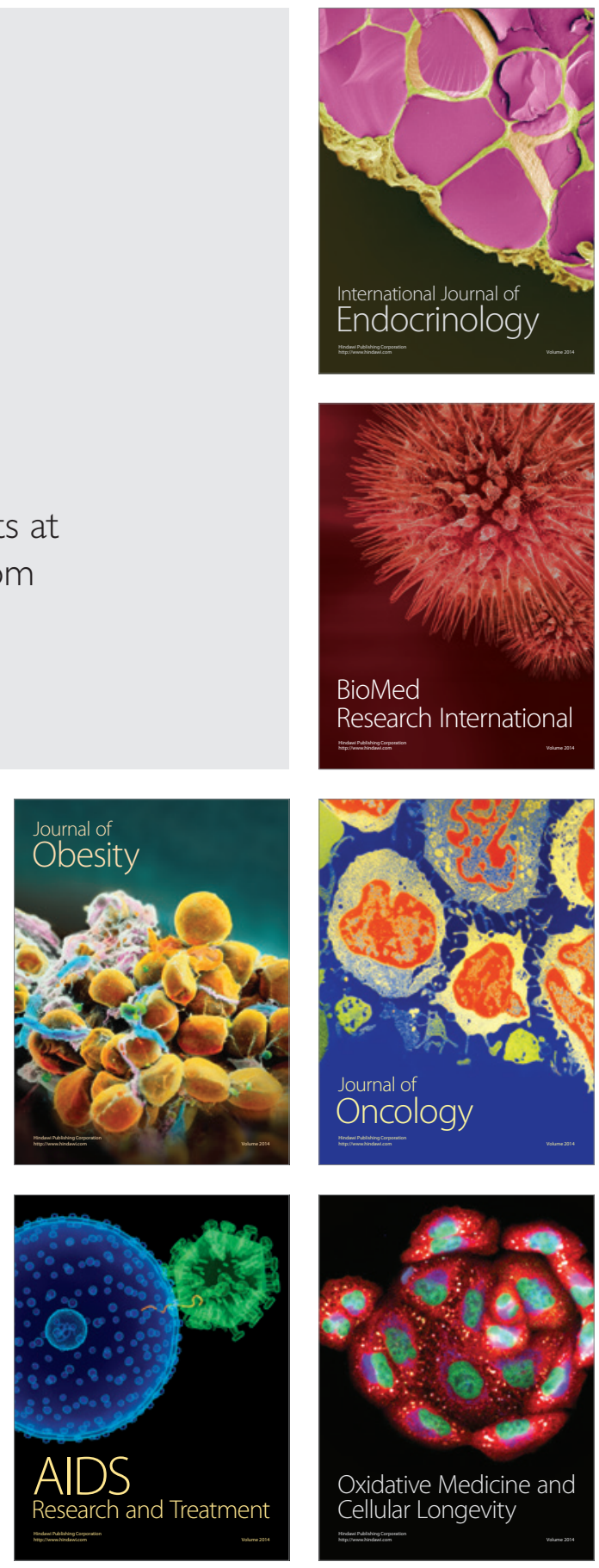